Family Medicine and Community Health

\title{
Comparison of general practice residents' attitudes and perceptions about training in two programmes in China: a mixed methods survey
}

\author{
Siqing Lian, ${ }^{1} \mathrm{Yu} \mathrm{Xia},{ }^{2}$ Jinzhi Zhang, ${ }^{2}$ Xiaoning Han, ${ }^{3}$ Chunhua Chi, ${ }^{4}$ \\ Michael D Fetters (D) ${ }^{5}$
}

To cite: Lian S, Xia Y, Zhang J, et al. Comparison of general practice residents' attitudes and perceptions about training in two programmes in China: a mixed methods survey. Fam Med Com Health 2019;7:e000238. doi:10.1136/ fmch-2019-000238

\section{Check for updates}

(c) Author(s) (or their employer(s)) 2019. Re-use permitted under CC BY-NC. No commercial re-use. See rights and permissions. Published by BMJ.

${ }^{1}$ General Practice Department, Peking University First Hospital, Peking, Xicheng District, China ${ }^{2}$ General Practice Department, Peking University Shenzhen Hospital, Shenzhen, Guangdong, China

${ }^{3}$ Cardiology Department, Peking University First Hospital, Peking, Xicheng District, China

${ }^{4}$ Department of General Practice, Peking University First Hospital, Peking, Xicheng District, China

${ }^{5}$ Department of Family Medicine, University of Michigan, Ann Arbor, Michigan, USA

Correspondence to Dr Chunhua Chi; 1504246723@qq.com

\section{ABSTRACT}

Objective To understand general practice (GP) residents' attitudes about their residency training in China.

Design Mixed methods survey administered crosssectionally.

Setting Two GP training programmes similar in most regards according to current GP training policy of 5 years' undergraduate degree in medicine and 3 years of postgraduate GP residency training - but differing as the Beijing programme has adopted educational innovations beyond the nationally prescribed standard curriculum used by the second Shenzhen programme.

Participants 105 (85\%) of eligible GP trainees, 35 (90\%) in the innovative Beijing programme and $70(83 \%)$ in the standard training Shenzhen programme.

Results Overall, residents felt discrimination because of specialty choice, and that they lacked competency as a general practitioner. Many residents commented faculty had negative teaching attitudes. Beijing residents were more satisfied than Shenzhen residents with their training $(p=0.001)$, and felt teaching faculty had sufficient knowledge $(p<0.001)$, and appropriate attitudes towards teaching $(p=0.004)$. Beijing residents more strongly agreed on five items about good future job prospects (all $p<0.05$ ). Conclusion These Chinese GP residents identify areas for improvement in their training as well as strengths. Higher satisfaction with faculty teaching and job optimism in Beijing where GP residents receive training from specifically qualified faculty, and can earn special certification, suggest that the educational innovations enhance training and promote positivity about job prospects. These findings imply that GP residents in China face many training challenges that are similar to other international reports, while also implicating benefits of using an innovative curricular approach.

\section{INTRODUCTION}

Since 2010, increasingly the Chinese government has made training of general practitioners a priority to help resolve the nation's healthcare provider shortage. The aim of general practice (GP) residency training is to provide trainees with the skills necessary to practise fully as general practitioners. In 2011, the State Council of the People's

\section{Key points}

- The researchers used a mixed methods crosssectional survey to compare general practice (GP) residents' attitudes about their training in two different residency training programmes in China, one an educationally innovative 'Four-Certificates-In-One' programme in Beijing, and the other, a typical training programme in Shenzhen.

- The researchers conducted a mixed methods analysis to understand the views of residents across the programmes using a survey, to understand GP residents' perspectives about the domains of interest and to link these findings together to achieve an understanding of the breadth and depth of the GP residents' opinions.

- The study findings imply that GP residents in China face many training challenges that are similar to findings in other international reports, while also implicating benefits of using an innovative curricular approach.

Republic of China strengthened the training requirements of general practitioners by implementing standardised training. ${ }^{1}$ Since December 2013, every medical student needs to complete residency training to become an independent physician. ${ }^{2}$ As an illustration of the commitment by the government, in September 2018, the National Health Commission of the People's Republic of China mandated that all general hospitals that were already qualified to provide standardised residency training needed to establish a GP department by the end of December 2019 or face cancellation of the hospital's training certification. ${ }^{3}$

The Chinese Medical Doctor Association commissioned Wu et al (2018) to examine 72 training programmes in 19 provinces that were developed to trial standardised GP residency training by the National Health and Family Planning Commission. ${ }^{4}$ In the 2017 
annual evaluation report they found that most of the GP training programmes were complying with the training requirements, but $50 \%$ of hospitals had not established an independent GP department, and in many programmes, the GP training was indistinguishable from other disciplines. The qualifications of the GP teaching faculty varied greatly as most were from other specialties and had not trained sufficiently in GP teaching. The report concluded the educational background and experiences of faculty in the community health centres needed improvement. ${ }^{4}$

Depending on the geographic location, GP residency training has different characteristics, financial support and training pathways in China. For example, in a survey of five well-known Chinese GP training institutions, the authors reported that the first GP residency training programme began in Beijing, and that Guangdong has the largest scale of training. ${ }^{5}$ The degree of government financial support for GP training varies by province. For example, in 2012, the highest level of government financial support per programme amounted to $¥ 560000$ (about US\$88900) in Chongqing, and $¥ 150000$ (about US\$23800) in Beijing, ${ }^{5}$ while there was no financial support in Sichuan..$^{5}$ Lian et at have documented eight pathways used to train general practitioners in China, but the government has encouraged mostly the ' $5+3$ ' pathway. ${ }^{6}$ The $5+3$ pathway comprises 5 years of undergraduate training in medical sciences conferring a Bachelor of Science degree and then 3 years of postgraduate and clinical training. In 2013, the government chose 64 medical colleges, including Peking University First Hospital, to pilot a "Four-Certificates-In-One programme" that encompasses a physician qualification certificate, standard residency training certificate, master's degree certificate and graduate certificate. Completion of the programme confers a higher level of qualifications based on additional requirements during residency. ${ }^{7}$

As GP residency training remains relatively new in China, the attitudes of GP residents about their training could provide a perspective on how the training process affects those the system is intended to educate. Previous literature concerning GP residency training has addressed a series of concerns including job burnout, ${ }^{8}$ training satisfaction, ${ }^{9-11}$ policy support, theory courses, and faculty qualifications, ${ }^{9} 10$ opportunity to learn management of diseases, ${ }^{10}$ personal values, income level, career development, social respect, and professional risk during GP residency training, ${ }^{11} 12$ as well as perspectives about GP residency training, ${ }^{9}$ and factors affecting standardised training quality. ${ }^{13}$ One previous qualitative study examining work-family balance by women GP specialist trainees in Slovenia demonstrated they faced intense burdens at work and home. ${ }^{14}$ Little current literature addresses the workload of GP residency training, the emphasis of training for GP, the impact of GP residency training on physical health and daily life, and gender issues in GP residency training. In addition, few previous studies have leveraged the benefits of mixed methods data collection to examine the GP residents' perspectives about their residency training which have been conducted in China. ${ }^{9}{ }^{10}$ Most articles have used pure quantitative methods, ${ }^{811}$ or pure qualitative methods. ${ }^{14}$

Through this study, we sought to understand GP residents' attitudes and perceptions about GP residency training, and further to compare the findings between two $5+3 \mathrm{GP}$ residency programmes, one $5+3$ programme piloting the 'Four-Certificates-In-One' option in Beijing with the standard $5+3$ residency training approach at the other programme in Shenzhen.

\section{METHODS}

\section{Study design}

We used a state-of-the-art mixed methods survey that was administered cross-sectionally in April 2019. ${ }^{15}$ Our rationale for using a mixed data collection survey was the need to understand the views of residents across the programmes using the survey, to understand GP residents' perspectives about the domains of interest and to link these findings together to achieve an understanding of the breadth and depth of opinions.

\section{Setting}

We selected two GP training programmes for study, the Departments of Peking University First Hospital in Beijing, a $5+3$ programme also participating in the 'FourCertificates-In-One programme,' and Peking University Shenzhen Hospital in Shenzhen, China, which is a straight $5+3$ programme. Table 1 contrasts the Peking University First Hospital and Peking University Shenzhen Hospital relative to residency programme innovation, working environment, management, financial support and resident numbers. ${ }^{16-21}$

\section{Data instrument and data collection}

We distributed a survey used previously in comparisons of family medicine residents' attitudes about training in Japan and the USA,${ }^{22}$ and Ethiopia and the USA ${ }^{23}$ The original instrument addressed GP residents' demographics items, their attitudes towards GP residency training using 5-point Likert scale questions. ${ }^{22}{ }^{23}$ We expanded on the 43 items used previously to create a 54-item survey to adapt for compelling contemporary issues in China. Specifically, we added questions about future work prospects as a general practitioner $(\mathrm{n}=8)$, satisfaction with residency training $(n=2)$ and one additional question about gender issues in GP residency training. We also included openended qualitative questions after each of the scales and a final open-ended qualitative question at the end of the survey to encourage resident reporting of their perspectives and experiences.

\section{Participant recruitment and enrolment}

We sent a recruitment email describing the study to all GP residents and recent graduates for whom there was contact information of the two study programmes. Participants met inclusion criteria for participation if they 
Table 1 Comparison of selected features of the innovative general practice training programme of Peking University First Hospital with the standard general practice training programme of Peking University Shenzhen Hospital in 2019

\begin{tabular}{|c|c|c|}
\hline Characteristics & $\begin{array}{l}\text { Peking University First Hospital - an } \\
\text { innovative GP training programme }\end{array}$ & $\begin{array}{l}\text { Peking University Shenzhen Hospital - a } \\
\text { standard GP training programme }\end{array}$ \\
\hline $\begin{array}{l}\text { Hospital departments and } \\
\text { inpatient capacity }\end{array}$ & $\begin{array}{l}\text { Peking University First Hospital contains } 36 \\
\text { clinical departments, } 16 \text { medical technology } \\
\text { departments and } 6 \text { research institutes. It has } \\
64 \text { wards and } 1574 \text { beds in total. }{ }^{16}\end{array}$ & 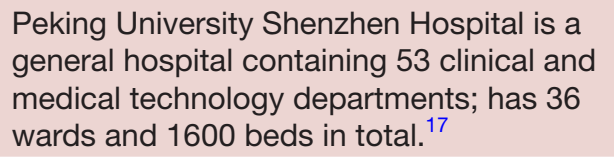 \\
\hline Clinical rotation* & 33 months total & 33 months total \\
\hline Outpatient training & 15.5 months & 12 months \\
\hline Residency programme innovation & $\begin{array}{l}\text { Combined with 'Four-Certificates-In-One' } \\
\text { programme† }\end{array}$ & $\begin{array}{l}\text { Invite family medicine international } \\
\text { physicians to improve teaching quality }\end{array}$ \\
\hline Education degree after training & Gain master's degree & Maintain bachelor's degree \\
\hline Management & $\begin{array}{l}\text { Have dependent general medicine } \\
\text { department }\end{array}$ & $\begin{array}{l}\text { General medicine department is combined } \\
\text { with emergency department }\end{array}$ \\
\hline $\begin{array}{l}\text { Number of mentors for GP } \\
\text { residents }\end{array}$ & 7 & 1 \\
\hline $\begin{array}{l}\text { Number of teaching faculty } \\
\text { assigned to teach residents in } \\
\text { clinic }\end{array}$ & 40 & 3 \\
\hline $\begin{array}{l}\text { Number of other specialists } \\
\text { who passed transfer training } \\
\text { requirements }\end{array}$ & 10 & 10 \\
\hline Number of GP residents & 18 in training, 21 graduates & 71 in training, 13 graduates \\
\hline
\end{tabular}

*The training duration complies with the national GP training requirement, 33 months in total. ${ }^{20}$ †After completing the programme, the residents receive a physician qualification certificate, residency standard training certificate, a master's degree certificate and a graduate certificate. ${ }^{21}$

GP, general practice.

reviewed the consent for participation, clicked the survey link and answered the study questions. Residents who declined to click the link and complete the survey were excluded.

\section{Data entry and analysis}

\section{Quantitative strand}

The quantitative findings were downloaded from the web link into the statistical software SPSS V.16.0 and cleaned. The major study outcomes were resident satisfaction with their education, and how they differed between sites. Demographics were compared between hospitals using $\chi^{2}$ tests or Fisher's exact test as appropriate. If the $p$ value was less than 0.05 , we interpreted this as a significant difference between these groups. Statistical analysis of the 5-point Likert scales comparing the residents' responses from the two sites was performed using independent group t-test for each of the seven major domains.

\section{Qualitative strand}

The qualitative data were downloaded into MSWord. The analysis was conducted using seven steps of the approach recommended by Bachuk. ${ }^{24}$ The text was then translated into English by a study author (SL) to facilitate participation of the international author. All translated English text segments were reviewed for fidelity to the original Chinese by a second author (MDF). As the amount of data was not excessive and did not require software, we analysed the text using manual coding with a priori codes based on the scales in the instrument, namely residency education, patient care, work independence, financial situation, personal situation, gender issues and future work as a general practitioner.

\section{Mixed methods}

As the qualitative questions were placed after each scale, we linked the qualitative findings to the overarching 
Table 2 Participant demographics in the innovative general practice training programme of Peking University First Hospital and the standard general practice training programme of Peking University Shenzhen Hospital

\begin{tabular}{|c|c|c|c|c|}
\hline Demographic variable & Total & $\begin{array}{l}\text { Peking University First Hospital } \\
\text { - an innovative GP training } \\
\text { programme }(n=35)\end{array}$ & $\begin{array}{l}\text { Peking University Shenzhen } \\
\text { Hospital - a standard GP } \\
\text { training programme }(n=70)\end{array}$ & $P$ value \\
\hline \multicolumn{5}{|l|}{ Gender } \\
\hline Male & 35 & 10 (64\%) & 25 (71\%) & 0.464 \\
\hline Female & 70 & $25(36 \%)$ & 45 (29\%) & \\
\hline \multicolumn{5}{|l|}{ Marital status } \\
\hline Single & 85 & 25 (71\%) & 60 (86\%) & 0.101 \\
\hline Married & 19 & 10 (29\%) & $9(13 \%)$ & \\
\hline Divorced & 1 & 0 & $1(1 \%)$ & \\
\hline \multicolumn{5}{|l|}{ Age (years) } \\
\hline $20-24$ & 1 & 0 & $1(1 \%)$ & 0.119 \\
\hline $25-29$ & 21 & $4(11 \%)$ & 17 (24\%) & \\
\hline 30-34 & 75 & $26(74 \%)$ & 49 (70\%) & \\
\hline 35-39 & 8 & 5 (14\%) & $3(4 \%)$ & \\
\hline 40 or more & 0 & 0 & 0 & \\
\hline \multicolumn{5}{|l|}{ Year of residency } \\
\hline First year & 30 & $7(20 \%)$ & $23(33 \%)$ & 0.001 \\
\hline Second year & 20 & 5 (14\%) & 15 (21\%) & \\
\hline Third year & 24 & $4(11 \%)$ & 20 (29\%) & \\
\hline Graduated & 31 & 19 (54\%) & 12 (17\%) & \\
\hline Total & 105 & 35 & 70 & \\
\hline
\end{tabular}

GP, general practice.

construct of each scale. We considered the quantitative and qualitative findings systematically such as to identify qualitative text to provide context for each scale while representing the breadth of responses, gender, and Chinese versus international background. We presented the mixed methods findings using a weaving approach, that is, quantitative scale and related qualitative findings addressing common constructs were considered together. ${ }^{24}$ We examined the 'fit' of the qualitative and quantitative data to look for confirmation, discordance and expansion. ${ }^{25}$

\section{RESULTS}

\section{Demographics}

The response rate at Peking University First Hospital was 90\% (35/39) and at Peking University Shenzhen Hospital was $83 \%(70 / 84)$. There were no significant differences between the programmes relative to gender, marital status and age between Beijing and Shenzhen. The percentage of residency graduates who took the survey was significantly greater in Beijing than in Shenzhen $(\mathrm{p}=0.001)$ (table 2) consequent to a loss of contact information for some Shenzhen graduates.

\section{Perceptions about resident education and patient care}

Overall, the residents frequently felt that the curriculum needed clarification (mean 1.97, SD 0.904), and frequently or sometimes felt that outpatient training was inadequate (mean 2.4, SD 1.140) (table 3). About patient care, the residents frequently or sometimes felt that there were too many inpatients.

On average, Beijing residents more frequently felt satisfied with their education than Shenzhen $(p=0.001)$. Five features of residency education attributes in Beijing were rated higher. Beijing residents felt more frequently that: their training programme would prepare them to work as a general practitioner $(\mathrm{p}=0.03)$, they had good role models $(\mathrm{p}=0.02)$ and teaching faculty had sufficient knowledge $(\mathrm{p}<0.001)$ and appropriate attitude towards GP training $(p=0.004)$. In contrast, Shenzhen residents felt more frequently that their inpatient training was excessive $(p=0.003)$ and that there were too many inpatients $(\mathrm{p}=0.01)$.

Qualitative comments about resident education were provided by $21(60 \%)$ Beijing residents and $22(28 \%)$ Shenzhen residents. Sixteen (45\%) Beijing residents and $16(22 \%)$ Shenzhen residents provided comments about patient care. Among them, four Beijing and 11 Shenzhen residents commented they needed more training time in outpatient care. But when care occurred, at least for some, there was another concern as voiced by a female Beijing resident who said:

There are too many outpatients to summarize the cases very well, and the teacher can't teach well. But 
Table 3 Family medicine residents' attitudes about residency education and patient care in the innovative general practice training programme of Peking University First Hospital and the standard general practice training programme of Peking University Shenzhen Hospital

\begin{tabular}{|c|c|c|c|c|}
\hline & $\begin{array}{l}\text { Overall } \\
(\mathrm{n}=105)\end{array}$ & $\begin{array}{l}\text { Peking University } \\
\text { First Hospital - an } \\
\text { innovative GP } \\
\text { training programme } \\
(\mathrm{n}=35) \\
\end{array}$ & $\begin{array}{l}\text { Peking University } \\
\text { Shenzhen Hospital } \\
\text { - a standard GP } \\
\text { training programme } \\
(\mathrm{n}=70) \\
\end{array}$ & \\
\hline & Mean (SD) & Mean (SD) & Mean (SD) & $P$ value \\
\hline \multicolumn{5}{|l|}{ How often have you felt... } \\
\hline \multicolumn{5}{|l|}{ Education } \\
\hline Satisfied with your education & $2.26(0.772)$ & $1.97(0.785)$ & $2.43(0.753)$ & 0.001 \\
\hline $\begin{array}{l}\text { Your training programme will prepare you to } \\
\text { work as a general practitioner }\end{array}$ & $2.03(0.882)$ & $1.83(0.985)$ & $2.16(0.845)$ & 0.034 \\
\hline You had good role models & $2.10(0.876)$ & $1.86(0.810)$ & $2.24(0.892)$ & 0.022 \\
\hline $\begin{array}{l}\text { Our general practice training curriculum } \\
\text { needs clarification }\end{array}$ & $1.97(0.904)$ & $2.03(0.891)$ & $1.91(0.913)$ & 0.362 \\
\hline $\begin{array}{l}\text { Your training goals for each rotation were } \\
\text { clear }\end{array}$ & $2.71(0.958)$ & $2.57(1.008)$ & $2.79(0.931)$ & 0.282 \\
\hline Inpatient training was excessive & $4.09(1.057)$ & $4.51(0.781)$ & $3.87(1.115)$ & 0.003 \\
\hline Outpatient training was inadequate & $2.40(1.140)$ & $2.60(1.063)$ & $2.33(1.213)$ & 0.366 \\
\hline $\begin{array}{l}\text { Teaching faculty had sufficient knowledge to } \\
\text { train GP residents }\end{array}$ & $1.91(0.748)$ & $1.54(0.611)$ & $2.10(0.745)$ & 0.000 \\
\hline Faculty had an appropriate attitude & $2.10(0.784)$ & $1.80(0.719)$ & $2.26(0.774)$ & 0.004 \\
\hline Academically overwhelmed & $3.18(0.969)$ & $3.31(0.932)$ & $3.11(0.986)$ & 0.321 \\
\hline \multicolumn{5}{|l|}{ Patient care } \\
\hline There were too many inpatients & $2.76(0.956)$ & $3.09(0.951)$ & $2.60(0.923)$ & 0.013 \\
\hline There were too few inpatients & $3.77(0.869)$ & $3.57(0.850)$ & $3.87(0.867)$ & 0.096 \\
\hline There were too many outpatients & $3.31(1.095)$ & $3.31(1.022)$ & $3.33(1.139)$ & 0.851 \\
\hline There were too few outpatients & $3.80(0.870)$ & $3.74(0.780)$ & $3.84(0.911)$ & 0.478 \\
\hline Clinical decision-making rewarding & $1.86(0.790)$ & $1.69(0.631)$ & $1.96(0.859)$ & 0.066 \\
\hline Patient management rewarding & $1.86(0.814)$ & $1.66(0.684)$ & $1.97(0.868)$ & 0.041 \\
\hline The doctor-patient relationship gratifying & $1.67(0.675)$ & $1.63(0.646)$ & $1.70(0.709)$ & 0.477 \\
\hline
\end{tabular}

Scale: $1=$ strongly agree, $2=$ somewhat agree, $3=$ neutral, 4=somewhat disagree, $5=$ strongly disagree.

GP, general practice.

even if there is time to teach, it is possible that they deal with cases in the specialist's way and cannot show general practitioners how to treat patients in clinic. Moreover, I hope my teachers can educate about consultation and follow-up skills which cannot be learned in the ward.

One resident in Beijing and seven in Shenzhen commented about negative faculty attitudes. For example, a female resident from Shenzhen commented, 'A teaching faculty member said that the general practitioner's role is to care for colds, and coughs-the job is very relaxed. They also ignore GP residents. In this situation, I felt discrimination.'

\section{Perceptions about independence as GP residents}

As shown in table 4, overall residents felt sometimes a 'lack of self-identity as a general practitioner', 'discrimination because of specialty choice' and 'lack competency as a general practitioner'. As illustrated in table 3, there were no significant differences between Shenzhen and Beijing residents from perceptions about independence as GP residents. Qualitatively, $16(45.7 \%)$ residents in Beijing and 16 (23\%) in Shenzhen provided comments about independence as GP residents. One Beijing and four Shenzhen residents commented that they disagreed with managing patients independently during residency training for they were inexperienced. One male Beijing resident commented:

Nowadays, [regarding] the work of residents after Bachelor of Science degree, they cannot be given much responsibility because their patient management experience is limited. Asking for advice is necessary-as seniority grows, [they] can have more 
Table 4 Family medicine residents' attitudes about independence as a general practice resident in the innovative general practice training programme of Peking University First Hospital and the standard general practice training programme of Peking University Shenzhen Hospital

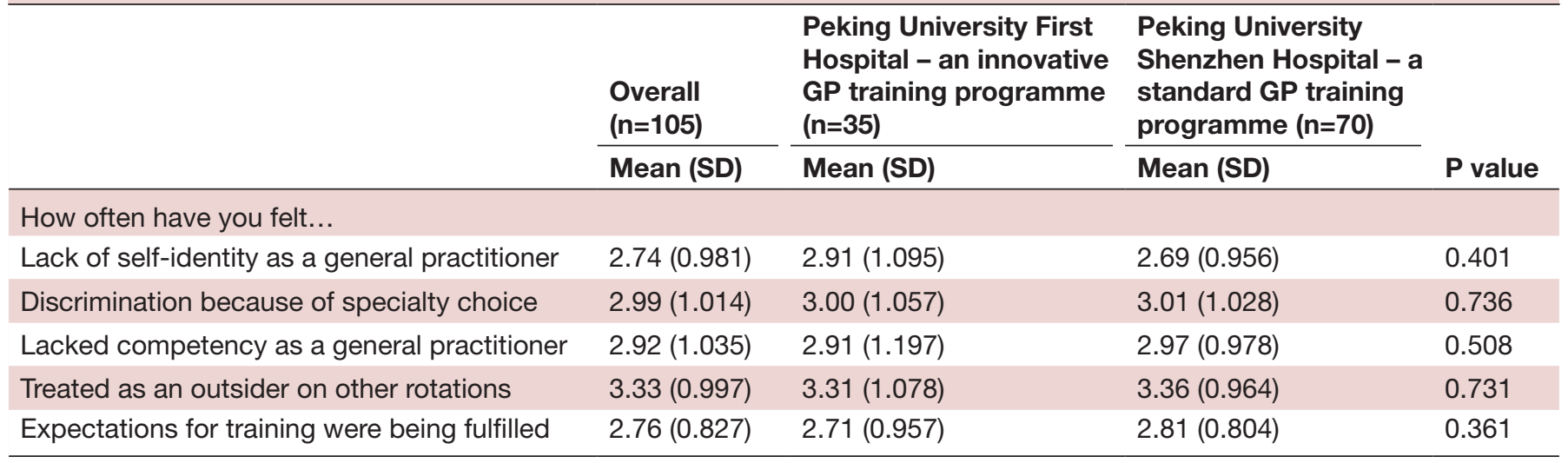

Scale: $1=$ strongly agree, $2=$ somewhat agree, $3=$ neutral, 4=somewhat disagree, $5=$ strongly disagree. GP, general practice.

responsibility. But GP residents only have one year of rotations in the ward and will leave the ward after having grown up.

\section{Impact of residency training on personal life}

As in table 5, the residents overall felt they lacked sufficient financial support during residency training (average score $<3)$. About their personal life, residents sometimes felt sleep deprived. There were no significant differences between Shenzhen and Beijing residents relative to their perceptions about finances and personal lives (table 5). Qualitative responses about finances were provided by $22(34 \%)$ Beijing residents and 12 (17\%) Shenzhen residents. Six residents in Beijing and four in Shenzhen commented that their payment needed to be increased or was too low. For example, a female Beijing resident said, 'Can improve the payment properly, after all, residents do the most fatiguing work with the least salary.' Ten (29\%) Beijing residents and 11 (16\%) Shenzhen residents provided comments about their personal life. About their personal life, one Beijing and one Shenzhen resident felt despised or looked down on.

\section{Perceptions about future work prospects}

As shown in table 6, the residents agreed or were neutral that they would be respected by other physicians as a general practitioner in the future career. In the training programme comparison, Beijing residents on average were more positive on five items addressing future work optimism. They agreed at a higher level they would have job opportunities $(\mathrm{p}=0.005)$, would be able to practise the same spectrum of care as their training $(p=0.02)$, would be paid fairly for their work as a general practitioner $(p=0.003)$ and would be respected by patients $(p=0.006)$ and other physicians in the future as a general practitioner $(\mathrm{p}=0.001)$.

Qualitative responses about future work as a general practitioner were provided by $10(29 \%)$ Beijing residents and $7(16 \%)$ Shenzhen residents. Five Beijing residents while only one Shenzhen resident commented working as a general practitioner would have a bright future. A female Beijing resident said, 'The employment prospects in big cities are good.' Two Shenzhen residents and one Beijing resident commented the future is not good enough. A female Shenzhen resident commented:

[The future job] is not clear. Community clinics have too many administrative and public health jobs. At present, we have been doing clinic check-ups, registration, recording data, filling out forms. We do not have any further understanding of GP. Now I have found a job, [and will] wait and see what happens. It is not in line with my expectations. I may look for opportunities to transfer to a hospital.

Three Beijing residents and one Shenzhen resident commented that the spectrum of training cannot prepare them to become a good general practitioner. Two Beijing and four Shenzhen residents demanded more respect from the society and other medical specialists. One female Beijing resident commented, 'I hope to get the recognition from society, at least [respect for my] identity from peers.'

\section{Gender issues in GP training}

Overall, the residents felt gender issues arose infrequently (table 7). There were no differences between Beijing and Shenzhen residents on seven items about gender differences. However, subanalysis by gender showed that in Shenzhen, male residents more frequently felt that being a female general practitioner provides an advantage $(p=0.006)$, while female residents there more frequently felt that being a male general practitioner provides an advantage $(\mathrm{p}=0.05)$. Qualitative findings confirmed these findings. Ten (29\%) Beijing and 7 (10\%) Shenzhen residents responded about gender issues. Seven Beijing and two Shenzhen residents said treatment of males and females was the same. 
Table 5 General practice residents' attitudes about finances and personal life according to training site and gender of the respondents in the innovative general practice training programme of Peking University First Hospital and the standard general practice training programme of Peking University Shenzhen Hospital

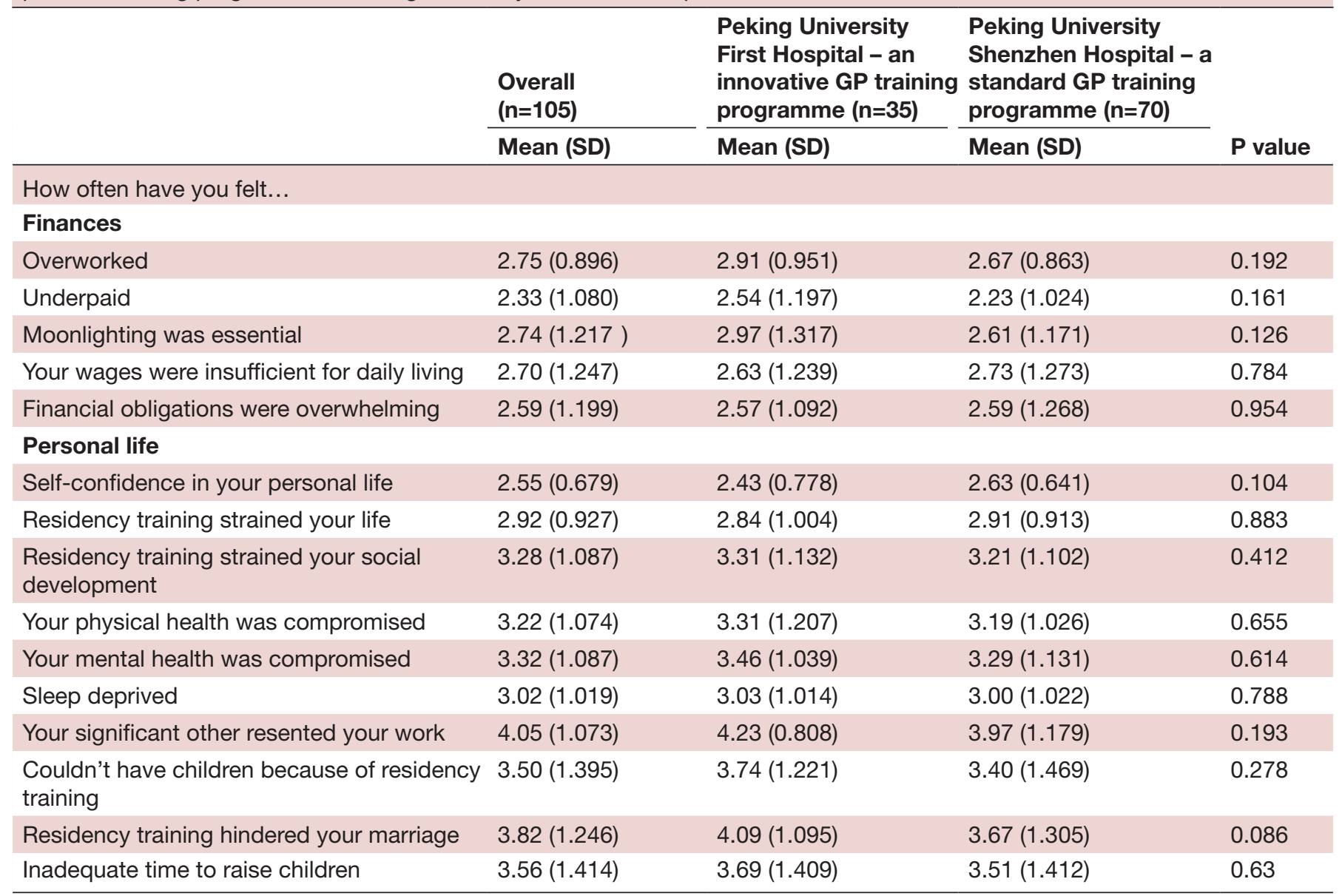

Table values (except for $p$ values) represent a mean on 5-point scale.

Scale: $1=$ all the time, $2=$ frequently, $3=$ sometimes, $4=$ infrequently, $5=$ never. GP, general practice.

\section{DISCUSSION}

GP is a discipline newly developing in China, still with limited numbers of residents and relative inexperience educating them. ${ }^{26}$ As important stakeholders, GP residents' attitudes provide an important reference for improving GP residency education.

\section{Overall trends in attitudes across the two Chinese GP training programmes}

Overall, the residents identify challenges of lack of respect, discrimination, achieving competency as general practitioners and negative teaching faculty attitudes. Their concerns are validated by previous literature. In large Chinese hospitals, doctors receive higher salaries, have higher reputations and have better career opportunities than general practitioners. ${ }^{26}$ The educational level in hospitals is higher than community health organisations. ${ }^{6}$ These factors likely contribute to lower social status, but do not justify pejorative attitudes.

Feelings of incompetence seem attributable to a lack of sufficient clinical experience. While GP residents manage patients in the ward, they only have 1 year of ward rotations while other residents spend more time there. Currently, most GP residents only shadow in the clinic, while other residents can manage outpatients. These findings reinforce the importance of more hands on clinical experience for GP residents, of having trained teaching physicians as important for improving resident competency, ${ }^{27}$ and for teaching faculty to have an unbiased attitude towards GP residents and give them equal opportunities to practise.

In a previous study examining family medicine resident attitudes in Japan and America, faculty knowledge and teaching attitudes were associated with improved resident satisfaction. ${ }^{22}$ Specifically, a sample of residents in America felt discrimination because of their choice of family medicine in 1991, but in 1995, both Japanese and American residents reported less feelings of discrimination. ${ }^{22}$ These findings suggest that respect from other specialists can be improved. In Gossa et als cross-national study of USA and Ethiopia (where family medicine only began in 2013), most differences in views about residency education among the US and the Ethiopian groups were 
Table 6 General practice residents' attitudes about work prospects according to training site and respondent gender in the innovative general practice training programme of Peking University First Hospital and the standard general practice training programme of Peking University Shenzhen Hospital

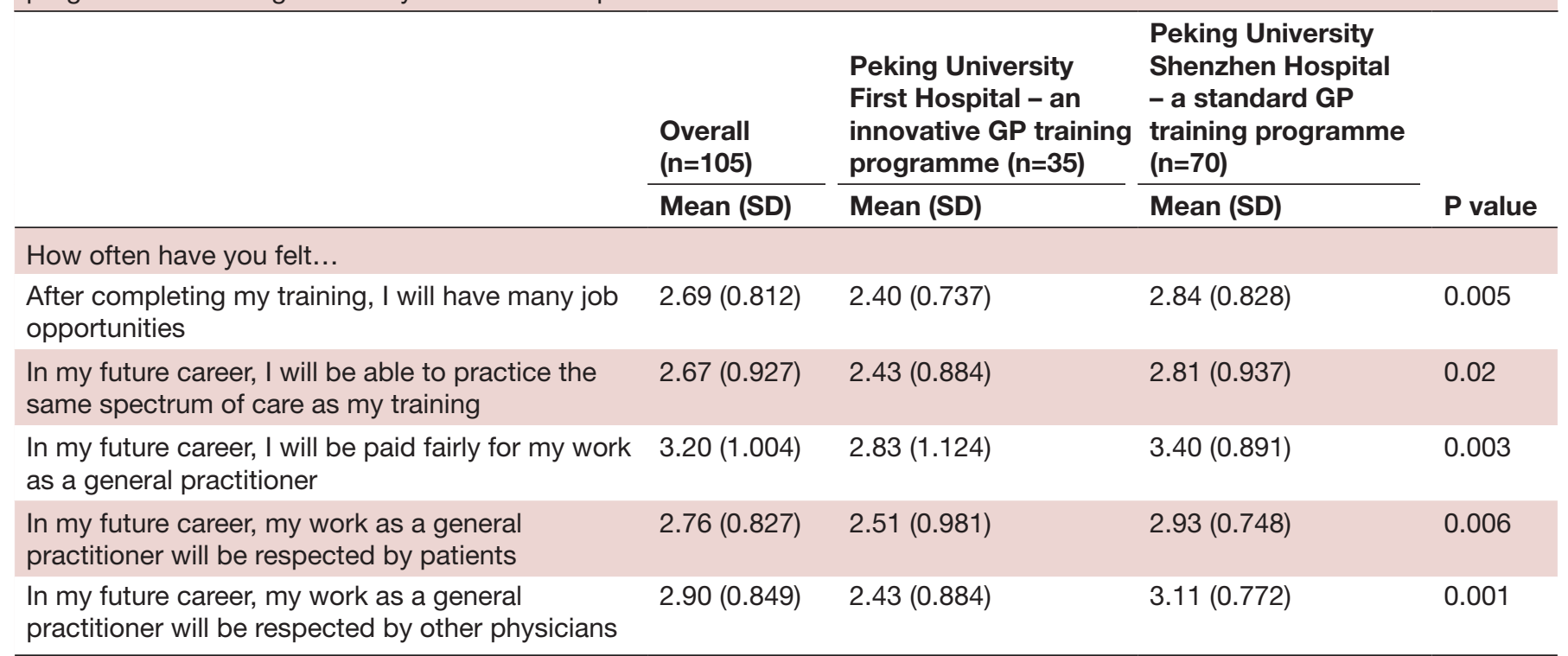

Table values (except for $p$ values) represent a mean on 5-point scale.

Scale: $1=$ strongly agree, $2=$ somewhat agree, $3=$ neutral, $4=$ somewhat disagree, $5=$ strongly disagree.

GP, general practice.

overall not significant, but the Ethiopian residents were more frequently satisfied with their residency education than residents in a comparison programme in the USA $(p=0.07) .{ }^{23}$ These findings imply that even if the education system is in an early stage of development, resident satisfaction with education can be influenced positively depending on the circumstances of the program.

\section{Differences between the two programmes}

Compared with the standard $5+3$ programme of Shenzhen, Beijing residents who benefit from the $5+3$ and FourCertificates-In-One programming more frequently felt satisfied with their education, and that teaching faculty had sufficient knowledge and appropriate teaching attitudes. Even though most teaching faculty in GP in Beijing are from other specialties and lack experience teaching GP residents, their affiliation with the culture of the academically rigorous Peking University Health Science Center might influence teaching faculty knowledge and training attitudes. The GP training system in Peking University First Hospital improved after strict selection of faculty. ${ }^{18}$ Nearly 20 specialists who were candidates to become GP resident teaching faculty took part in transfer training, but only half of them earned a GP certificate, a status conferring qualification to work in a GP clinic. These findings support the importance of educating other specialists as GP trainers. ${ }^{28}$

Overall, Beijing residents more favourably perceived their future job prospects as general practitioners. While we cannot conclusively attribute causality of the differences to availability of the Four-Certificates-In-One system, these findings suggest that the intensive training of faculty, and the additional opportunities through the
'Four-Certificates-In-One' programme positively impact Beijing resident optimism about job prospects compared with Shenzhen residents who lack the same opportunity.

These differences aside, for the majority of items examined, for example, training content, finances, personal life and gender issues, there were no substantial differences between the residents' attitudes in Beijing and Shenzhen. Indeed, the residents in both programs indicated favourable ratings for a number of items. The lack of differences suggests their overall ratings may reflect the status of GP training in China more generally. For example, in Liu's study in Shanghai, 55.8\% (125/224) of residents felt their outpatient time was insufficient, $54.0 \%(121 / 224)$ of residents wanted more opportunities to manage patients independently and $24.3 \%$ (111/457) of GP residents felt the teaching faculty did not have sufficient understanding of general medicine philosophy. ${ }^{9}$ In Wang et al's study, 59.4\% (76/128) of GP residents felt the educational content was too specialised. ${ }^{11}$

\section{Addressing the challenge of other specialist discrimination}

These findings illustrate a problem with, or at least the perception of specialists discriminating against GP residents. In Huang et al's (2018) study, among 768 GP residents, only $57.8 \% \quad(n=444)$ reported they would like to continue to work as general practitioners in the future, and overall, they reported negative attitudes about the level of social respect. ${ }^{13}$ Among 288 medical students in Wang et $a l{ }^{1}{ }^{11}$ study, $24.7 \%(\mathrm{n}=71)$ of students felt general practitioners had lower social status, and $28.5 \%(n=65)$ of students felt general practitioners could not gain respect from other physicians. ${ }^{29}$ Unfortunately, similar challenges exist even in mature international settings. 
Table 7 General practice residents' attitudes about gender issues according to training site and gender of the respondents in the innovative general practice training programme of Peking University First Hospital and the standard general practice training programme of Peking University Shenzhen Hospital

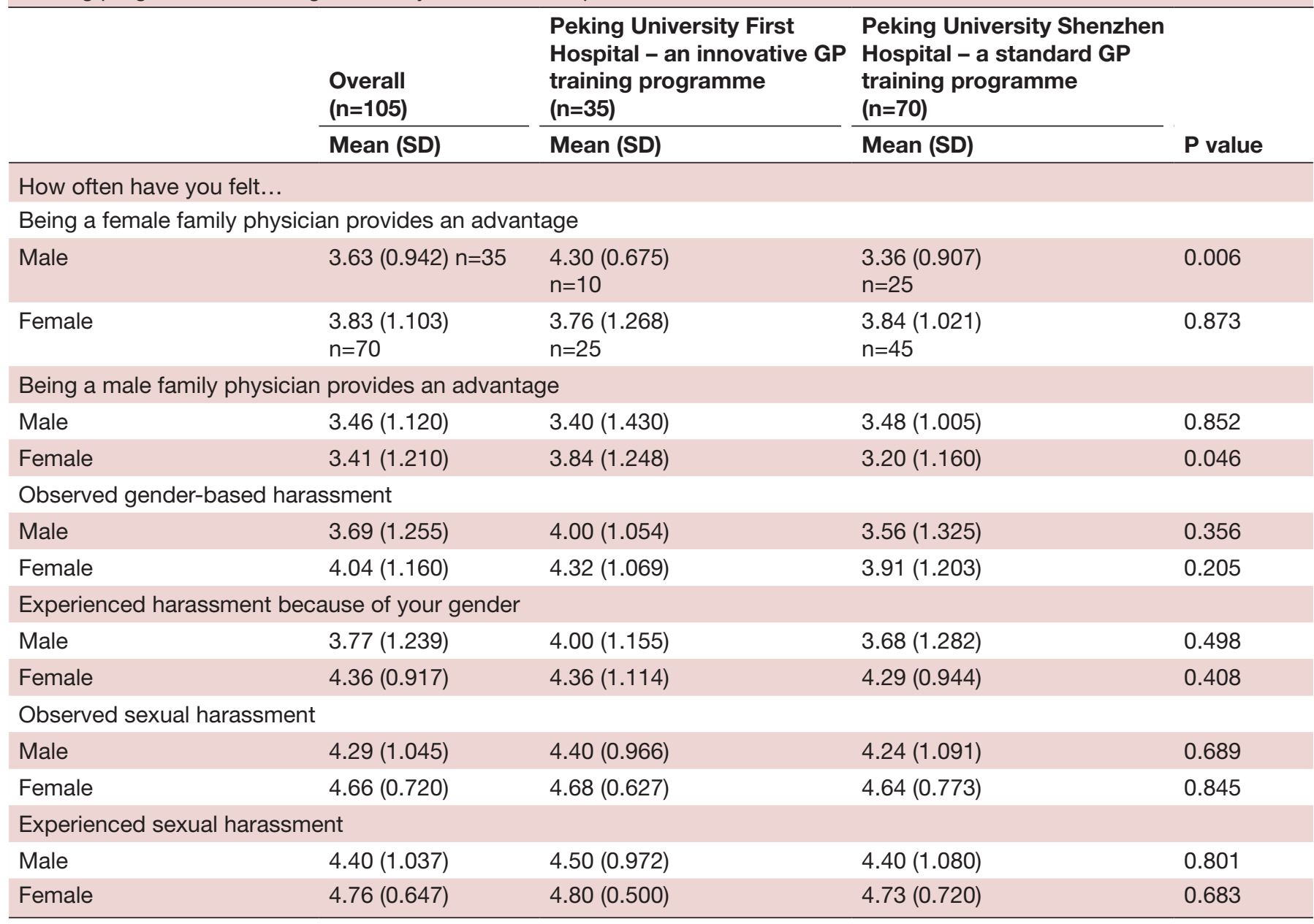

Scale: $1=$ all the time,

$2=$ frequently,

3=sometimes,

$4=$ infrequently, $\quad 5=$ never.

GP, general practice.

On the bright side, it appears proactively intervening can improve relations. In Alberta College, Canada, family physicians perceived a lack of respect. ${ }^{30}$ An intervention implemented by the faculty of medicine department and family medicine department improved relationships between general practitioners and other specialists; improved support of each other's roles; changed negative attitudes by promoting the expertise and role of family medicine to others; and demonstrated maintenance of comprehensive skills. ${ }^{30}$

\section{Strength and limitations}

To our knowledge, this study represents the first intentionally designed mixed data collection survey in the field of primary healthcare in China. The study demonstrates one example of many mixed methods research designs that can be used in primary healthcare. ${ }^{31}{ }^{32}$ The use of scales followed by qualitative questions to provide a more comprehensive understanding about the construct of interest provides a model for other researchers to use in mixed data collection surveys.
In this study, the quantitative findings measured the frequency of attitudes about survey items, and allowed for statistical comparison between the two programmes. In addition, the qualitative findings provided a more nuanced understanding about the study scale results. We recommend researchers in other countries consider using mixed methods designs in their work to fully explore the complexities of traning and clinical practice. A mixed methods approach may be particularly useful for investigating the complexity and reality of issues in low and middle-income countries.

While the study was conducted in only two residency sites, these were chosen specifically to compare two $5+3$ programmes, one with the Four-Certificates-In-One educational innovation versus a typical programme. Future research in more programmes with this innovation could provide additional insight, though many of these findings resonate with previous resident surveys in Japan and the USA, ${ }^{22}$ and Ethiopia and the USA. ${ }^{23}$ 


\section{CONCLUSIONS}

Creating and nurturing respectful relationships between general practitioners and other specialists connotes a critical priority for alleviating many challenges in GP training. These findings show higher satisfaction with faculty teaching and higher job optimism in the Beijing programme with educational innovations. In sum, these findings reinforce the value of educational innovations for enhancing training and promoting optimism among residents for future work as general practitioners.

\section{Twitter Michael D Fetters @mdfetters}

Acknowledgements The authors gratefully acknowledge Melissa A. Plegue, who provided statistical consultation guiding the analysis.

Contributors SL, YX, CC and MDF contributed to the planning of the study. SL, YX, $\mathrm{JZ}$ and $\mathrm{XH}$ contributed to collection of data for the study. SL, YX, JZ, XH, CC and MDF contributed to the authoring and reporting of the study findings.

Funding This study was funded by University of Michigan Medical School. Competing interests None declared.

Patient consent for publication Not required.

Ethics approval The study was reviewed and approved by the Peking University First Hospital Human Research Ethics Committee. Ethical review number: (2019) Scientific research number 89.

Provenance and peer review Not commissioned; externally peer reviewed.

Data availability statement There are no data in this work.

Open access This is an open access article distributed in accordance with the Creative Commons Attribution Non Commercial (CC BY-NC 4.0) license, which permits others to distribute, remix, adapt, build upon this work non-commercially, and license their derivative works on different terms, provided the original work is properly cited, appropriate credit is given, any changes made indicated, and the use is non-commercial. See: http://creativecommons.org/licenses/by-nc/4.0/.

ORCID iD

Michael D Fetters http://orcid.org/0000-0001-8521-5681

\section{REFERENCES}

1 State Council. 国务院关于建立全科医生制度的指导意见 [State Council's guidance on establishing a general practitioner system]. Available: http://www.gov.cn/zwgk/2011-07/07/content_1901099. htm [Accessed 3 Jun 2019].

2 National Health Commission of the People's Republic of China. 《住 院医师规范化培训基地认定 准 (试行) 》和《住院医师规范化培训内容 与准 (试行) 》文件解读[Interpretation of the "Resident Standardized Training Base Certification Standard (Trial)" and "Resident Standardized Training Contents and standards (Trial)"]. Available: http://www.nhc.gov.cn/zwgk/jdjd/201408/2466fd51be4e4bcba7c4 d8c03a9514d3.shtml [Accessed 21 May 2019].

3 National Health and Wellness committee. 住院医师规范化培训基地 ( 综合医院) 全科医学科设置指导 准 (试行) 政策解读[Interpretation of the standardized training standard (trial) of the resident standardized training base (general hospital)]. Available: http://www.nhc.gov.cn/ zwgk/jdjd/201408/2466fd51be4e4bcba7c4d8c03a9514d3.shtml [Accessed 11 Mar 2019].

4 Wu S, Shi R, Du X, et al. Analysis of annual evaluation results of 2017 standardized residency training bases of general practice. Chinese $J$ Grad Med Educ 2018;2:6-9.

5 Zhang D, Liu Y, He P, et al. Survey on status quo of 5 standardized training bases of our country " $5+3$ " general practitioners. Chongqing Medicine 2017;28:3953-6.

6 Lian S, Chen Q, Yao M, et al. Training pathways to working as a general practitioner in China. Fam Med 2019;51:262-70.

7 National Health Science and Education. 《关于建立住院医师规范 化培训制度的指导意见》[Guidance on establishing a standardized training system for residents]. Available: http://www.gov.cn/gzdt/ 2014-01/17/content_2569096.htm [Accessed 22 Aug 2019].

8 Huang L, Hu S, Wang $\mathrm{H}$, et al. Study on the relation of job burnout and turnover intention in the resident physician of general standardized training program. Shanghai Medicine 2017;38:7-11.
9 Liu J. Retrospective Analysis on general practitioners standardized training of graduated general practitioners in Shanghai [Doctoral dissertation in Shanghai Fudan University], 2014.

10 Wu L, Qi H, Wu J, et al. Analysis on different general practitioner training mode effect. Chinese Journal of Health Education 2013;29:428-40.

11 Wang YY, Wang RY, Zhang JJ, et al. Satisfaction of trainees with the standardized general practitioner training delivered by the general practice department of a general Hospital. Chinese General Practice 2018;568:94-8.

12 Zou LL. Analysis of satisfaction degree to standardized training and primary hospitals in undergraduate of 2010 from Zunyi Medical College [Doctoral dissertation in Zunyi College, 2018.

13 Huang MJ, Qiu K, Bao R, et al. General medical students career confidence index in China. Chinese General Practice 2018;21:3123-7.

$14 \mathrm{Ma} \mathrm{L}$, Li Y, Yao H. Influencing factors analysis on training quality of standardized training of general (assistant) practitioners in Xinjiang. Chinese Health Quality Management 2016;23:18-20.

15 Creswell JW, Hirose M. Mixed methods and survey research in family medicine and community health. FMCH 2019;7:e000086.

16 Peking University First Hospital. Hospital introduction. Available: https://www.pkufh.com/Html/News/Articles/1198.html [Accessed 21 May 2019].

17 Peking university Shenzhen Hospital. Hospital introduction. Available: https://www.pkuszh.com/yyjj/index_21.aspx?from=singlemessage\& isappinstalled $=0$ [Accessed 21 May 2019].

18 Dong A, Qi Z, Qi J, et al. The exploration and practice of general practice residents standardized training in Peking university health science center. Chinese Journal of General Practice 2018;16:149-51.

19 Peking University Shenzhen Hospital Faculty Training Department. 师资培训, 共裹盛举一一全科长风, 浪有时 [Faculty training, cooperate together -face difficulties of General Medicine and strive forward]. Available: https://mp.weixin.qq.com/s/HO06zskbglyzhtT6 OyXkvg [Accessed 8 Jun 2019].

20 National Defense Office Science and Education. 住院医师规范化 培训内容与 准 (试行 ) Resident standardized training content and standards (trial). Available: http://www.nhc.gov.cn/ewebeditor/ uploadfile/2014/08/20140825155108969.PDF [Accessed 20 May 2019].

21 Ministry of Education of the People's Republic of China. 教育部, 国家卫生计生委有关负责人就《关于

医教协同深化临床医学人才培养改革的意见》答记者问[Person in charge of the Ministry of Education and the National Health and Family Planning Commission answered questions on the "Opinions on the Cooperation of Medical Education and Cooperation to Deepen the Reform of Clinical Medical Talents"]. Available: http://old. moe.gov.cn/publicfiles/business/htmlfiles/moe/s271/201411/178872. html [Accessed 13 May 2019].

22 Fetters MD, Kitamura K, Mise J, et al. Japanese and United States family medicine resident physicians' attitudes about training. General Medicine 2002;3:9-16.

23 Gossa W, Jones C, Raiculescu S, et al. Family Medicine Residents' Attitudes About Training in Ethiopia and the United States. Fam Med 2019;51:424-9.

24 Bachuk WA. Fundamentals of qualitative analysis in family medicine. FMCH 2019;7:e000040.

25 Fetters MD, Curry LA, Creswell JW. Achieving integration in mixed methods Designs-Principles and practices. Health Serv Res 2013;48:2134-56.

26 Wang H, Gusmano MK, Cao Q. An evaluation of the policy on community health organizations in China: will the priority of new healthcare reform in China be a success? Health Policy 2011;99:37-43.

27 Hauer KE, Nishimura H, Dubon D, et al. Competency assessment form to improve feedback. Clin Teach 2018;15:472-7.

28 Fetters MD, Chi C, Hu L. Insights on developing general practice education in China. Acad Med 2017;92.

29 Wang H, Zhao Y, Lu X, et al. 临床医学专业本科生全科医 学知识及态度调查[Investigation of knowledge and attitude to general practice of Clinical Medical Undergraduates]. Chinese Journal of General Practice 2012;10:1927-9.

30 Manca D. Respect from specialists concerns of family physicians. Can Fam Physician 2008;10:1434-5.

31 Creswell JW, Plano Clark VL. Designing and conducting mixed methods research. 3rd edn. Thousand Oaks, CA: Sage, 2018.

32 Fetters MD. The mixed methods research workbook-Activities for designing, implementing, and publishing projects. Thousand oaks, CA: Sage, 2020. 
Correction: Comparison of general practice residents' attitudes and perceptions about training in two programmes in China: a mixed methods survey

Lian S, Xia Y, Zhang J, et al. Comparison of general practice residents' attitudes and perceptions about training in two programmes in China: a mixed methods survey. Fam Med Com Health 2019;7:e000238. doi:10.1136/fmch-2019-000238

Since the online publication of this article the authors have noted several corrections needed throughout the article.

On page two in the section 'Data instrument and data collection', the number of survey items in the third sentence is '52-item survey'. The number in the fourth sentence on the questions about future prospects is 5 . In the fifth sentence the number of additional items on gender issues is 2 . On page 8 , in the section 'Differences between the two programmes', in sentence four the number of those trained is 40 . On page 10 , reference 24, the author's name is 'Babchuk'.

In table 2, the correct percentages are ' $29 \%$ ' for males, and ' $71 \%$ ' for females at Peking University First Hospital, and '36\%' for males, and '64\%' for females at Peking University Shenzhen Hospital. In tables 3 and 4, the Likert Scales are 1=all the time, $2=$ frequently, $3=$ sometimes, $4=$ infrequently, $5=$ never. In table 6 , the initial column phrase 'How often have you felt...' should be 'Do you agree that...' In table 3 , the $p$ value of 'Teaching faculty had sufficient knowledge to train GP residents' is $\leq 0.01$; the mean (SD) of 'There were too many outpatients' in Peking University First Hospital is 3.29 (1.017). In table 4, the Overall Mean (SD) of 'Discrimination because of specialty choice' is 3.01 (1.028). In table 5, the Mean of 'Residency training strained your life' in Peking University First Hospital is 2.94. In table 7, the mean (SD) of female 'Experienced harassment because of your gender' in Peking University First Hospital is 4.48 (0.872); the overall mean of male 'Experienced sexual harassment' is 4.43.

Open access This is an open access article distributed in accordance with the Creative Commons Attribution Non Commercial (CC BY-NC 4.0) license, which permits others to distribute, remix, adapt, build upon this work non-commercially, and license their derivative works on different terms, provided the original work is properly cited, appropriate credit is given, any changes made indicated, and the use is non-commercial. See: http://creativecommons.org/licenses/by-nc/4.0/.

(c) Author(s) (or their employer(s)) 2020. Re-use permitted under CC BY-NC. No commercial re-use. See rights and permissions. Published by BMJ.

Fam Med Com Health 2020;8:e000238corr1. doi:10.1136/fmch-2019-000238corr1 